\title{
Effect of desliming on the flotation of a complax copper ore from China
}

\author{
Yong $\mathrm{CHEN}^{1, a}$, Yong Sheng SONG ${ }^{1}$, Wen Juan $\mathrm{Li}^{1}$ and Gui Ying ZHOU ${ }^{1}$ \\ ${ }^{1}$ National Engineering Laboratory of Biohydrometallurgy, General Research Institute for Nonferrous Metals, No.2 Xinjiekouwai Street, \\ Beijing, China
}

\begin{abstract}
The complex copper oxide ore sample was taken from Deerni copper deposit, Qinghai Province of China. Batch flotation tests had been conducted to upgrade the copper concentrate by conventional amyl xanthate reagents under $73 \%-74 \mu \mathrm{m}$ of the particle size; however, the unsatisfied results $(\mathrm{Cu}$ grade of $18.21 \%$ and recovery of $59.25 \%$ ) were obtained. Also there are a large amount of slimes trapped in the concentrate and high-dosages consumption of reagents, for example, more than $2.5 \mathrm{~kg} / \mathrm{t}$ sodium sulfide and $1.5 \mathrm{~kg} / \mathrm{t}$ sodium silicate at only one-staged roughing. Based on the analysis of the sample, most of gangues are clay, feldspar and mica, which may easy to over-grind and deteriorate the flotation process either on reagents consumption or slurry fluidity or viscosity. A hydro-cyclone had been introduced to pre-concentrate the oxide ore by scrubbing the slime before flotation, which can result obviously in reducing the dosages of sodium sulfide from $2.5 \mathrm{Kg} / \mathrm{t}$ to $1 \mathrm{Kg} / \mathrm{t}$, and raising the grade of $\mathrm{Cu}$ in the concentrate from $18.21 \%$ to $26.65 \%$ at the expense of about $1 \%$ recovery of $\mathrm{Cu}$. In this paper, the effects on the recovery of $\mathrm{Cu}$ by the different dosages of flotation reagents with or without de-sliming were studied, with the objective of determining the different effects on the functions of flotation reagents by slime during flotation.
\end{abstract}

\section{Introduction}

The flotation of oxidized $\mathrm{Cu}$ minerals, is much more difficult than the flotation of corresponding sulfide minerals. Several factors may influence oxidized $\mathrm{Cu}$ minerals recovery during flotation, such assist dissemination and composition, particles size[1-3], flotation reagents, especially sodium sulfide, temperature of slurry effected on the behavior of collectors, especially fatty acid [4-5].

Sulfide compounds have long been used in oxide type base-metals mineral flotation practice for decreasing the level of metal species in solution and for modifying the surface of the mineral while still having a surface that will respond to flotation. Sodium sulfide is the most important reagents in oxidized $\mathrm{Cu}$ minerals flotation [6-8]. The surface characteristics of tenorite in sodium sulfide solutions have been investigated in detail by HerreraUrbina et al. Sulfidization of the mineral surface significantly improves the flotation of tenorite with amyl xanthate as collector. The xanthate flotation of both sulfidized tenorite and malachite, however, is strongly affected by the sulfide dosage. Once the sulfide ion reports to the solution at the end of the conditioning period, mineral flotation ceases [5]. Both dispersion and depression were also found for sodium silicate $[3,6]$. However, the only problem for the use of sodium silicate in oxidized $\mathrm{Cu}$ ore flotation is how to reduce its dosage in order to filter concentrate smoothly and fast.

Particle size has also been a subject of research for flotation of tenorite and malachite. The different sensitivities to the reagent concentration for fine $(-400 \#)$ and coarse particles during phosphate ore flotation had been found by Santana et al. for carbonated and siliceous ores [9], slime has a very detrimental effecton the flotation of solids, which includes contaminating foams, raising the consumption of flotation reagents, reducing the speed of the process and causing an anarchic response in mineral separation.

Although the use of sodium sulfide and sodium silicate in copper oxide minerals flotation is well established, one of the main problems in phosphate ore in China is high-consumption of sodium sulfide, which is generally range from 5 to $8 \mathrm{~kg} / \mathrm{t}$, about $50 \%$ of total flotation agent cost [4-8], especially the mechanism between reagents and particles size and are not sufficiently understood. Singh et al. [9] indicated that "Spilt conditioning" can improve the flotation efficiency of slime (-37 micron) and coarse particles $(-105+44$ micron) due to hydrophobic aggregation between coarse particles and slimes from the Maton rock phosphate plant, India. Santana et al. [8] reported that the size of mineral particles plays a significant role in the sequence of events that lead to the flotation of a particle.

\footnotetext{
${ }^{a}$ Corresponding author: cy040311@163.com
} 
The aim of this paper is to investigate effect on dosages of sodium sulfide and sodium silicate in flotation of copper-oxide by slime from a Deerni copper deposit ore in order to gain a better understanding of the behavior of different particle sizes in flotation performance when adding the flotation reagents.

\section{Expertimental}

\subsection{Materials}

The copper oxide ore was provided by Deerni copper deposit, Qinghai province of China, in which the main gangue were clay, feldspar and mica. Around $200 \mathrm{~kg}$ of representative ore samples was crushed to below $2 \mathrm{~mm}$ size with two-stage jaw crusher and one-stage roll crusher. The materials were then well mixed and divided into $1 \mathrm{~kg}$ samples for mineralogical and pre-concentration studies.

Table 1. List of the experimental conditions of flotation tests.

\begin{tabular}{|c|c|}
\hline \multicolumn{2}{|c|}{ Experimental conditions } \\
\hline Constants & $3 \mathrm{~L}$ XF-D \\
\hline Cell type & $30 \%$ (mass) \\
\hline Feed ore concentration & $70 \%-74 \mu \mathrm{m}$ \\
\hline Feed size & $10 \mathrm{~min}$ \\
\hline $\begin{array}{c}\text { Flotation time } \\
\text { (rougher) }\end{array}$ & $1200 \mathrm{rpm}$ \\
\hline \begin{tabular}{c} 
Impeller speed \\
\hline \multicolumn{2}{|c|}{ Variables }
\end{tabular} \\
\hline Dispersant & Sodium silicate \\
\hline Sulfurizing reagent & Sodium Sulphide \\
\hline Collector & Amyl xanthate \\
\hline Frother & Pine camphor oil \\
\hline
\end{tabular}

Sodium sulphide was reagent-grade chemicals supplied by Kunming chemical reagent company. Sodium silicate was from metallurgical research centre of Kunming, which modulus was about 2. Amyl xanthate as collector was also from the same company.

\subsection{Methods}

\subsubsection{De-sliming tests}

$1 \mathrm{~kg}$ sample was mixed with $600 \mathrm{ml}$ tap water and ground to $75 \%-74 \mu \mathrm{m}$ in the ball mill, and then the pulp was diluted to $15 \%$ Solids and then fed to the hydro-cyclone (FX 25-PU Hydro-cyclone). The pressure was about $100 \mathrm{kPa}$. The underflow from the hydro-cyclone was collected. A size analysis for the overflow from FX-25 PU by dry and wet-sieving had been conducted by a series of screens from 400 mesh to 200 mesh.

\subsubsection{Bench flotation tests}

Flotation tests were conducted in a 3.0L XF-D cell. In a typical ore sample flotation test, $1 \mathrm{~kg}$ sample mixed with a certain amount of tap water was ground to $70 \%-74 \mu \mathrm{m}$ for several minutes in the ball mill, then diluted to $3.0 \mathrm{~L}$ cell XF-D which had been used to conduct roughing at $1200 \mathrm{rpm}$ for a certain time.

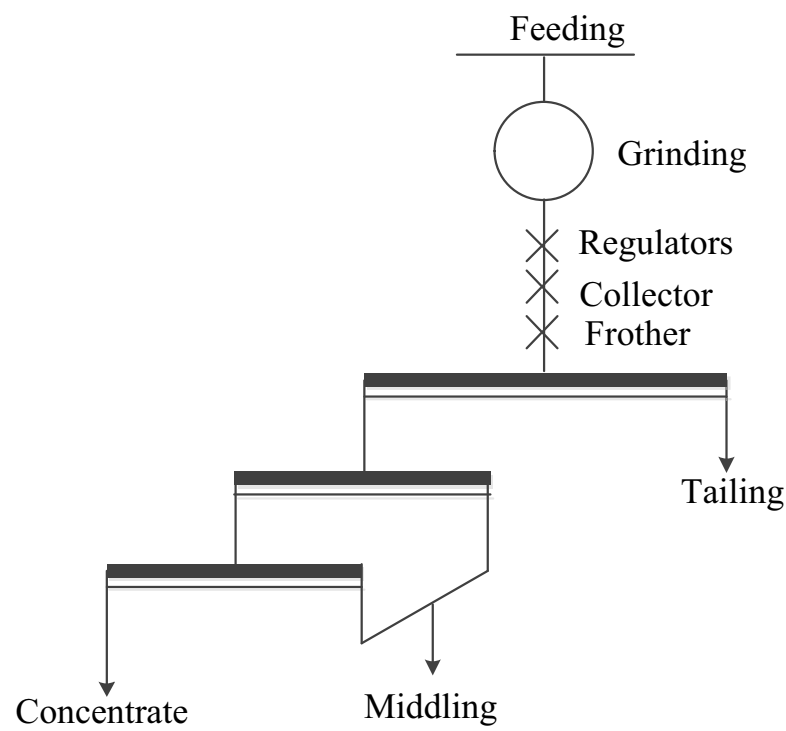

Figure 1. Flotation flowsheet

The flotation reagents had been added in the following order: depressants, collectors, before adjust the $\mathrm{pH}$ to a certain value by soda ash or hydrochloric acid as shown in Table 1, which presents the experimental conditions of bench flotation tests. In addition, the signs of Conc., Mid. and Tail. In the results from the flotation tests mean the concentrate, the total middlings included middling I, II and III and the total tailings involving the tailings from the flotation tests and the slime from hydrocyclone if scrubbing was used before flotation tests.

\section{Results and discussions}

\subsection{Size distribution}

Figure 2 shows the distribution of the particles copper oxide in the different size fractions of the head-feed ore samples without grinding. As can be seen, most of copper oxide minerals distribute in the relatively coarse fractions, such as more than $80 \%$ of copper oxide minerals at the fraction of $+74 \mu \mathrm{m}$, especially about $50 \%$ of copper oxide mineral sat the fraction of $+210 \mu \mathrm{m}$, which indicated that it is necessary to grind the sample to ensure the reasonable liberation of value minerals before the bench flotation tests are conducted. 


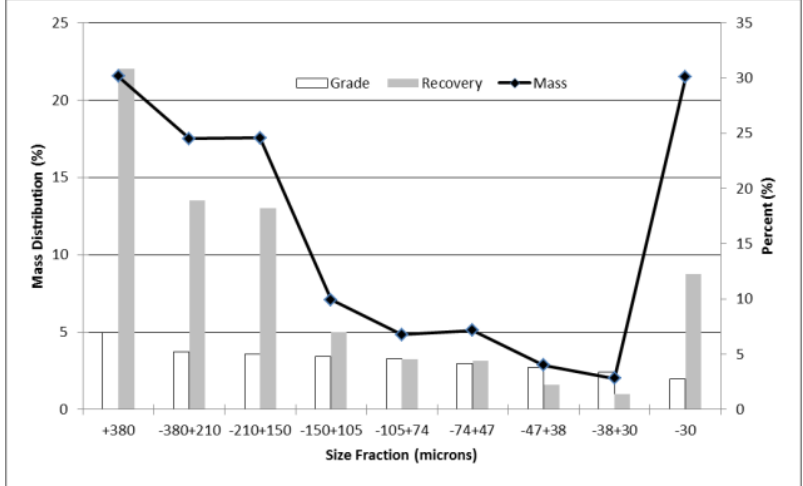

Figure 2. Size-assays, mass and $\mathrm{Cu}$ distributions of sample at different size fractions

Figure 3 presents the distribution of the copper oxide minerals at different size ranges at 200 mesh $73 \%$, which indicated that a sharply increase in the mass and recovery either at the fraction of $-30 \mu \mathrm{m}$ or $-74+30 \mu \mathrm{m}$. In the meanwhile, the low content of $\mathrm{Cu}$ in the fraction of $30 \mu \mathrm{m}$ may be possible to remove the slime by scrubbing effectively which can remove $30 \%$ slime from the head feed to flotation at a loss of about $13 \%$ of $\mathrm{Cu}$ in the slime.

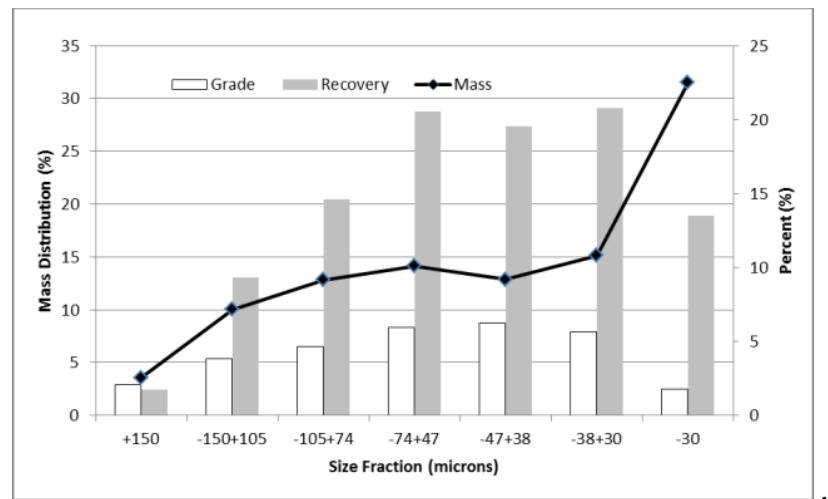

Figure 3. The distribution of the copper oxide minerals at different size ranges at 200 mesh $73 \%$

\subsection{De-sliming by hydro-cyclone}

In order to remove the slime, de-sliming tests were carried out. Size analysis of the underflow and overflow from FX 25-PU Hydro-cyclone by dry and wet-sieving had been presented in figue 4 . It was noted that only $28 \%$ of $\mathrm{Cu}$ and almost half of yields of feed distributed in the overflow. Also, $-38 \mu \mathrm{m}$ size fraction is the main mass in the overflow while $-105 \mu \mathrm{m} \sim+30 \mu \mathrm{m}$ size fraction is the main mass in the underflow. The de-sliming greatly reduces the fine mud, and create a good condition for subsequent flotation of underflow.

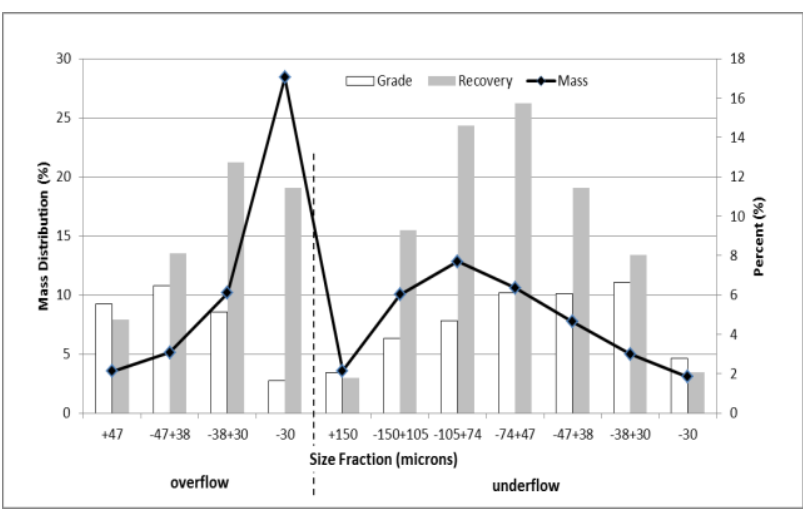

Figure 4. The size distribution of the underflow and overflow by de-sliming with FX 25-PU Hydro-cyclone.

\subsection{Flotation}

The flotation results without de-sliming was shown in Figure 5, which provides the grade and recovery of $\mathrm{Cu}$ in the concentrate, midding and tailing. As shown in Figue. 5 , this illustrates the unsatisfied results $(\mathrm{Cu}$ grade of $18.21 \%$ and recovery of $59.25 \%$ ) had been obtained. The better results $(26.65 \%$ grade of $\mathrm{Cu}$ at $58.24 \%$ recovery) had been obtained by de-sliming with FX 25-PU Hydrocyclone before flotation (show in Figure 6). De-sliming exhibited powerful effect on rising the grade of copper concentrate and little effect on the recovery of $\mathrm{Cu}$. Therefore, it could be an efficient measure before flotation by hydro-cyclone.

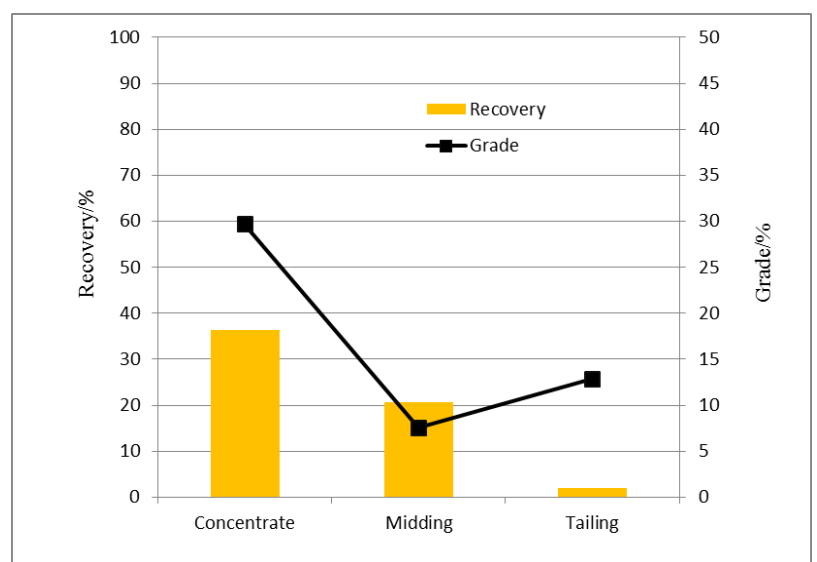

Figure 5. The flotation results without de-slimling

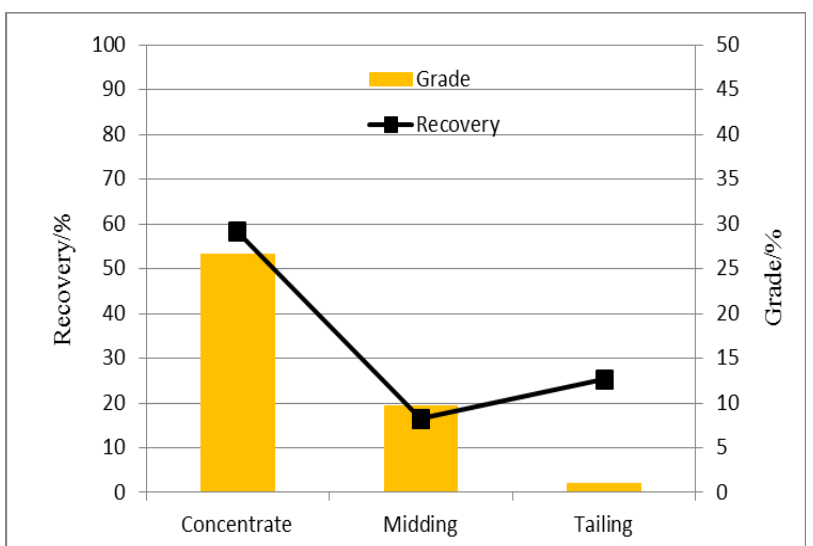

Figure 6. The flotation results of underflow by de-sliming with FX 25-PU Hydro-cyclone 


\subsection{Reagent consumption}

The reagent consumption results with or without deslimling before flotation was shown in figue 7. The flotation reagents consumption with de-sliming is much lower than without de-sliming, especially the amount of sodium sulphide and amyl xanthate. A hydro-cyclone had been introduced to pre-concentrate the oxide ore by scrubbing the slime before flotation reducing the dosages of sodium sulfide from $2.5 \mathrm{Kg} / \mathrm{t}$ to $1 \mathrm{Kg} / \mathrm{t}$, which saving reagent consumption greatly and improving the beneficiation indexes.

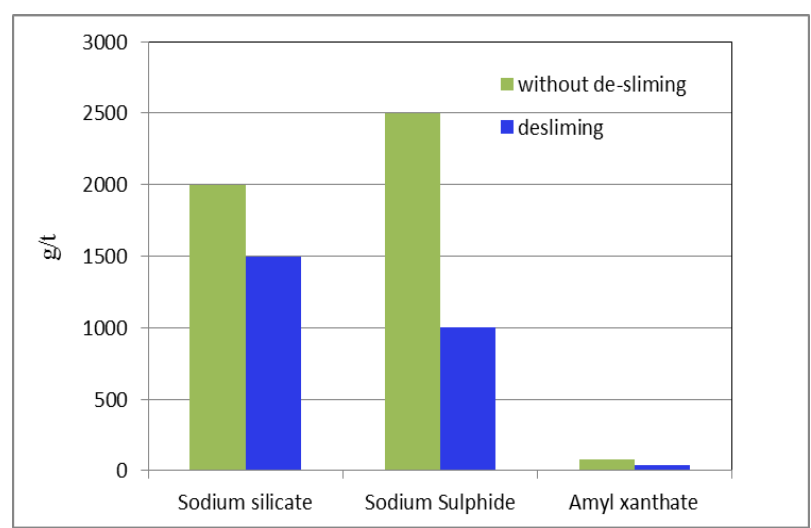

Figure 7. The reagent consumption results with or without deslimling

\section{Conclusions}

(1)An increase of $\mathrm{Cu}$ in the concentrate from $18.21 \%$ to $26.65 \%$ at saving about $1 / 2$ th original dosages of sodium sulphide and amyl xanthate was obtained by scrubbing.

(2) The consumption of sodium sulphide may be very sensible to the amount of slime in the pulp, so may sodium silicate and collector, which all reduce the dosages after de-sliming.

\section{Acknowledgments}

This work was financially supported by High and New Technology Industrialization promotion programs of Qinghai province, China (No. 2015-GX-Q06A).

\section{References}

1. Dos Santos, M A, Santana, R C and Cappoin, F, 2010. Effect of ionic species on the performance of apatite flotation, Separation and Purification Technology, 76: 15-20)

2. Feng, D and Aldrich, C, 2004. Influence of operating parameters on the flotation of apatite, Minerals Engineering, 17: 453-455)

3. Hernainz, F, Calero, M and Blazquez, G, 2004. Flotation of low-grade phosphate ore, Advanced powder technology, 15: 421-233.

4. F. De Lillo, F. Cecconi, G. Lacorata, A. Vulpiani, EPL, 84 (2008)
5. Houot, R, 1982. Beneficiation of phosphatic ores through flotation: review of industrial applications and potential development, International Journal of Mineral Processing, 9: 353-384

6. Santana, R C, Farnese, A C C and Fortes, M C B, 2008. Influence of particle size and reagent dosage on the performance of apatite flotation, Separation and Purification Technology, 64:8-15

7. Zhang, P, Yu, Y and Bogan, M, 1997. Challenging the "Crago" double float process II. Amine-fatty acid flotation of siliceous phosphates, Minerals Engineering, 10: 983-994

8. Yehia, A, Youseff, M A and Boulos, T R, 1999. Different alternatives for minimizing the collector consumption in phosphate fatty acid flotation, Minerals Engineering, 3: 273-278

9. Zheng, X and Smith, R W, 1997. Dolomite depressants in the flotation of apatite and cellophane from dolomite, Minerals Engineering, 10:537-545. XXVI 